\title{
Inhibition of 70/30 Brass Dezincification by Water-Soluble Organic Inhibitors
}

\author{
Takenori Notoya* \\ *Department of Metallurgy, Faculty of Engineering, Hokkaido University
}

\begin{abstract}
Five different types of copper or zinc complexing agents as water-soluble dezincification inhibitors for $70 / 30$ brass were tested by using a potentiostatic acceleration technique in $0.5 \mathrm{M} \mathrm{NaCl}$ solution containing an acetic acid-sodium acetate buffer solution of $\mathrm{pH} 4.43$ at $60^{\circ} \mathrm{C}$. Effectiveness of the inhibitors for preventing anodic dissolution of copper and zinc from 70/30 brass was in the following order; phytic acid $<$ octylhydroxamate potassium salt $<$ thioglycolic acid $<$ dimethyldithiocarbamic acid sodium salt $<$ benzotriazole. The inhibition mechanism of these inhibitors is probably due to the formation of copper and/or zinc complex films on the alloy surface. It is concluded that an addition of the most promising inhibitors such as benzotriazole to corrosive environments is an alternative method to prevent dezincification attack of 70/30 brass.
\end{abstract}

\section{Introductíon}

Brasses can usually be resistant to a variety corrosive environments including marine conditions. Variations in corrosion resistance of copper-zinc alloys can be correlated with differences in alloying element and their metallographic structure. Increasing the zinc content causes a tendency to increase dezincification attack. Attempts have been made to prevent or minimize dezincification attack of brasses by an addition of a small amount of alloying elements such as $\mathrm{Sn}, \mathrm{Sb}, \mathrm{As}, \mathrm{P}$ and/or heat treatment of manufactured components, and many commercial brasses have been developed to resist this form of corrosion. Dezincification, however, is still a problem.

Search was made for alternative techniques to protect brasses against dezincification attack by controlling corrosive environments with corrosion inhibitors. In the previous papers $\left.{ }^{1)}, 2\right), 3$ inhibitive action of many organic metal-complexing agents was evaluated as inhibitors for dezincification of $\alpha$ and $\alpha+\beta$ brasses using a potentiostatic acceleration technique. Several inhibitors tested showed effective inhibitive power for this purpose, such as 2-mercaptobenzimidazole and 2,5-dimercaptothiadiazole, but these inhibitors have disadvantage of sparingly soluble in water.

The aim of this study is to extend the feasibility of inhibitor application to prevent dezincification

* North 13, West 8, Sapporo, 060 Japan attack of $70 / 30$ brass with water-soluble inhibitors which are of importance for practical application. The inhibitors tested in the present paper included benzotriazole (BTA), phytic acid (PA), thioglycolic acid (TGA), dimethyldithiocarbamic acid sodium salt (DMDTC) and octylhydroxamate potassium salt (OHO). BTA is one of the excellent and widely used corrosion inhibitors for copper and its alloys ${ }^{4}$. PA has been used as a metal ion chelating agent as a food additive and has recently been used to prevent pitting attack for copper tubes $^{5)}$. TGA is one of the effective wet-stain inhibitors for zinc $^{6)}$. DMDTC has been used as a brass corrosion inhibitor ${ }^{7)}$ and as a flotation collector for zinc minerals. $\mathrm{OHO}$ is also an effective flotation collector for copper oxide minerals ${ }^{8)}$.

\section{Experimental}

Chemical structure of the organic inhibitors used is shown in Fig. 1. BTA is commercially available corrosion inhibitor of Cobratec- 99 which was supplied by Sherwin Williams Company. PA was supplied by Mitsui Toatsu Chemical Ind. Co, Ltd. TGA and DMDTC are analytical grade reagents from Wako Pure Chemical Industries, Ltd. and Tokyo Kasei Ind. Co, Ltd., respectively. OHO was synthesized by the procedure reported elsewhere ${ }^{8}$.

Dezincification test electrodes were milled from cold-rolled $70 / 30$ brass sheet to the size of $8.5 \times$ $9.5 \times 1.5 \mathrm{~mm}$. Chemical composition of the $70 / 30$ 
<smiles>c1ccc2[nH]nnc2c1</smiles>

Benzotriazole

( $B$ T A )

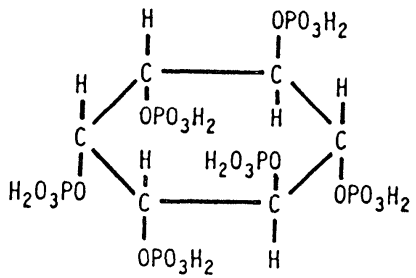

Phytic acid $(P A)$
$\mathrm{HS}-\stackrel{\stackrel{H}{\mathrm{C}}}{\dot{H}}-\mathrm{C} O \mathrm{O} O \mathrm{H}$

Thioglycolic acid

$(T G A)$<smiles>CN(C)C(S)S</smiles>

Dimetyl dithio carbamic acid sodium salt ( D MD T C )<smiles>[Y]ON=C([10BH2])O</smiles>

0ctyl hydroxamate potasslum salt

( $\mathrm{OHO}$ )

Fig. 1 Chemical structure of inhibitors used.

brass is as follows; $\mathrm{Cu} 70.62, \mathrm{Zn} 29.37, \mathrm{Sn}, \mathrm{Fe}$, $\mathrm{Pb} \leqq 0.005$. The electrode surface was mechanically abraded with No. $500 \mathrm{SiC}$ paper, degreased ultrasonically in acetone followed by washing in double-distilled water prior to test.

Dezincification measurements were conducted in air-saturated, non-stirred $0.5 \mathrm{M} \mathrm{NaCl}$ containing acetic acid-sodium acetate buffer solution with $\mathrm{pH} 4.43 \mathrm{kept}$ at $60^{\circ} \mathrm{C}$. The solution temperature was controlled within $\pm 0.5^{\circ} \mathrm{C}$ in a waterjacketed glass vessel containing $500 \mathrm{ml}$ of the test solution. A counter electrode was a sheet of platinum $(180 \times 10 \times 0.2 \mathrm{~mm})$ encircled around the brass electrode and potential of the electrode was measured against a saturated calomel electrode. The brass electrode was polarized to $-200 \mathrm{mV}$ vs. S.C.E. for 3 hours in the test solution. Under the condition dissolution rate of zinc from the brass is greater than that of copper, i.e., the dezincification is accelerated. The potentiostatic acceleration method gave reproducible results which were in good agreement with the types of dezincification in brasses observed under the most corrosive conditions in service ${ }^{9)}$. This is a modified technique of galvanostatically accelerated test in $0.5 \mathrm{M} \mathrm{NaCl}$ solution for determining the propensity to dezincification previously proposed by Marshakov and Bogdanov ${ }^{10)}$.

The effectiveness of the inhibitors was assessed by determination of amount of copper and zinc dissolved during the anodic polarization in the presence of inhibitor. Anodic current was recorded using Nichia model HP V100 potentiostat in conjunction with Hitachi recorder 056. The amount of copper and zinc dissolved in the solution was determined using Hitachi 170-50A atomic absorption spectrophotometer. Distribution of copper and zinc in the cross section of dezincified $70 / 30$ brass specimen was determined by JEOR JXA-50A electron probe microanalyzer.

\section{Results and Discussion}

1.1 Anodic current density- time behavior during anodic polarization

Anodic current change with time during polarization at $-200 \mathrm{mV}$ for the $70 / 30$ brass depends on the inhibitor used and its concentration. Fig. 2 shows typical behavior of anodic current density for $70 / 30$ brass in the presence and absence of BTA. In uninhibited solutions anodic current increased gradually with time in the initial period of polarization and reached a steady current after about $1 \mathrm{hr}$ polarization. The entire surface of the $70 / 30$ brass electrode became copperish in color. This current behavior suggests an increasing anodic dissolution of zinc and copper leaving behind a copper-rich surface followed by a steady growth of the dezincification layer. In inhibited solutions with BTA anodic current decreased with an increase of its concentration at concentrations greater than $10^{-6} \mathrm{M}$. Below this concentrations little change was seen in anodic cur- 
Vol. 35, No. 9

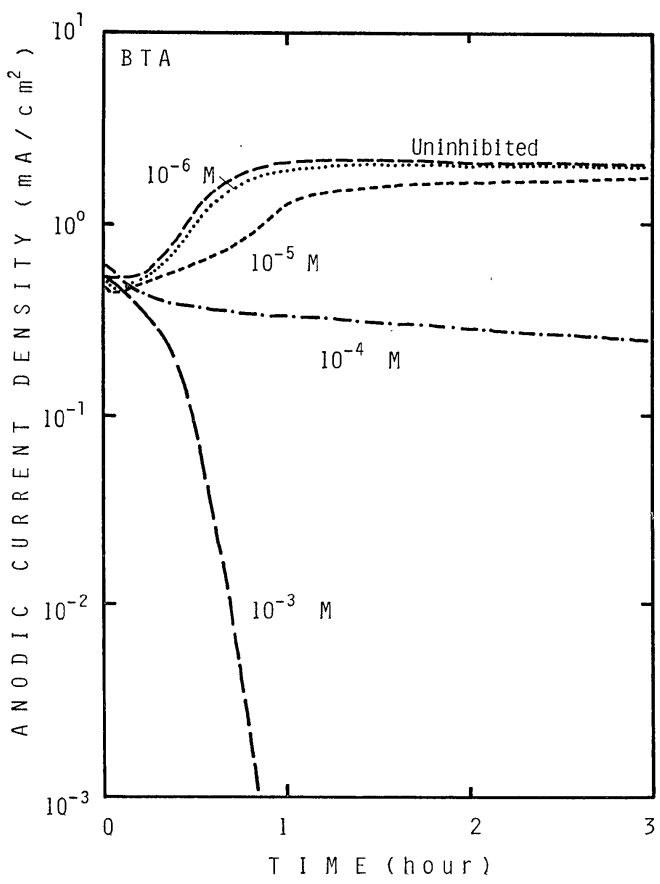

Fig. 2 Variation of anodic current density with polarization time at four different concentrations of BTA.

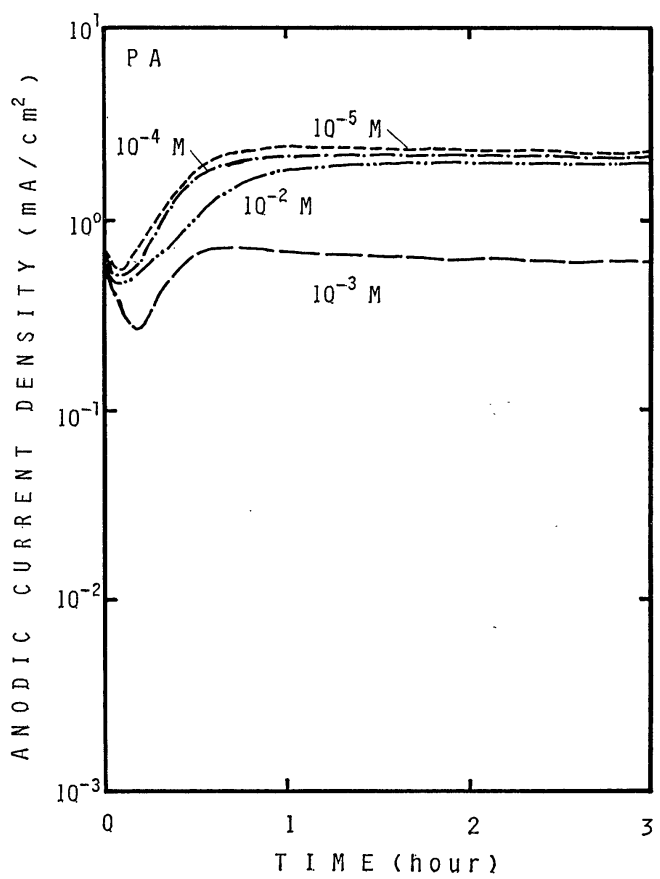

Fig. 3 Variation of anodic current density with polarization time at four different concentrations of PA.

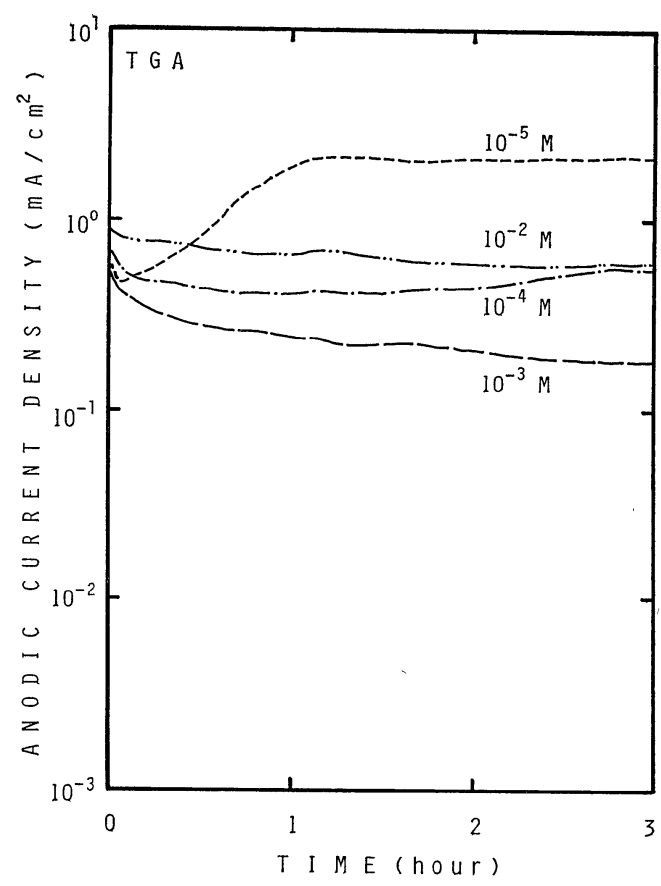

Fig. 4 Variation of anodic current density with polarization time at four different concentrations of TGA.

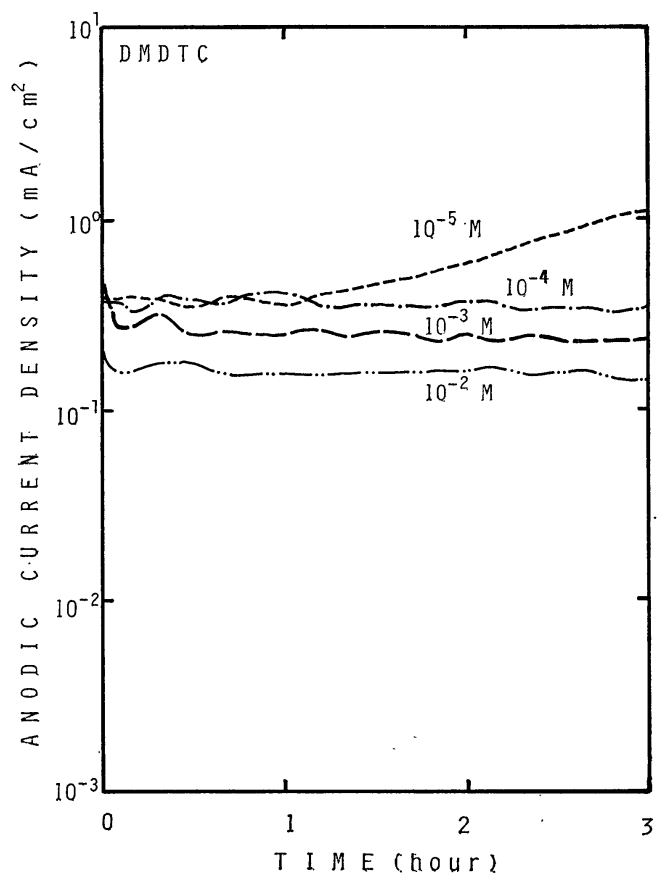

Fig. 5 Variation of anodic current density with polarization time at four different concentrations of DMDTC. 


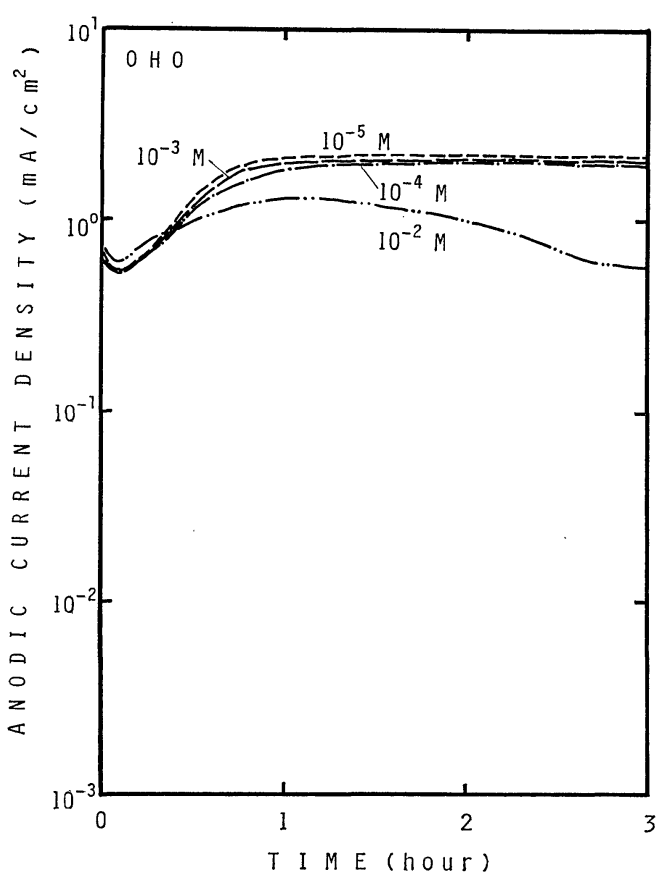

Fig. 6 Variation of anodic current density with polarization time at four different concentrations of $\mathrm{OHO}$.

rent behavior compared with uninhibited solutions. The anodic current density fell in the range of less than $1 \mu \mathrm{A} / \mathrm{cm}^{2}$ after $1 \mathrm{hr}$ polarization at concentrations of more than $10^{-3} \mathrm{M}$ for BTA. At these concentrations neither dezincified layer in the specimen nor any visible corrosion products on the surface were observed and the surface remained bright and specularly reflecting after $3 \mathrm{hr}$ polarization. Fig. 3 to 6 show variation of anodic current density with polarization time in the presence of the inhibitors used at four different concentrations in the range of $10^{-5}$ to $10^{-2} \mathrm{M}$. The anodic current behaviors of PA and TGA were similar; the anodic current decreased with increasing concentration of the inhibitor in the concentration range of $10^{-5}$ to $10^{-3} \mathrm{M}$ while at the concentration of $10^{-2} \mathrm{M}$ the anodic current increased. In the case of $\mathrm{OHO}$ and DMTDA the anodic current decreased with increasing concentration of the inhibitors in the concentrations tested. The concentration dependence of anodic current in these four inhibitors were much smaller than that of BTA.

\subsection{Copper and Zinc dissolved during anodic polarization}

Table 1 summarizes the amount of copper and zinc dissolved in the solution during anodic polarization and inhibition efficiency for the five inhibitors at concentrations of $10^{-5}$ to $10^{-2} \mathrm{M}$

Table 1 Inhibition efficiency of the inhibitors based on anodic dissolution of copper and zinc from $70 / 30$ brass at $-200 \mathrm{mV}$ in $0.5 \mathrm{M} \mathrm{NaCl}$ acetate buffered solution at $60^{\circ} \mathrm{C}$.

\begin{tabular}{|c|c|c|c|c|c|c|c|}
\hline Inhibitor & $\begin{array}{c}\text { Concentration } \\
(\mathrm{M} / 1)\end{array}$ & $\begin{array}{l}\text { Solution } \\
\mathrm{Cu} \\
\left(\mathrm{mg} / \mathrm{cm}^{2}\right)\end{array}$ & $\begin{array}{l}\text { analysis } \\
\text { } \mathrm{n} \\
\left(\mathrm{mg} / \mathrm{cm}^{2}\right)\end{array}$ & $\begin{array}{l}\text { Inhibi } \\
\mathrm{Cu} \\
(\%)\end{array}$ & $\begin{array}{l}\text { tion } \mathrm{e} \\
\mathrm{Zn} \\
(\%)\end{array}$ & $\begin{array}{l}\text { efficiency } \\
\begin{array}{c}\mathrm{Cu}+\mathrm{Zn} \\
(\%)\end{array}\end{array}$ & $\begin{array}{c}\text { Dezincification } \\
\text { factor } \\
z\end{array}$ \\
\hline Uninhibited & & 1.285 & 7.045 & - & - & $\longrightarrow$ & 13.2 \\
\hline B $T A$ & $\begin{array}{l}10^{-5} \\
10^{-4} \\
10^{-3} \\
10^{-2}\end{array}$ & $\begin{array}{l}1.188 \\
1.156 \\
0.245 \\
0.034\end{array}$ & $\begin{array}{l}6.250 \\
0.405 \\
0.163 \\
0.169\end{array}$ & $\begin{array}{r}7.5 \\
10.0 \\
80.9 \\
97.4\end{array}$ & $\begin{array}{l}11.3 \\
94.3 \\
97.7 \\
97.6\end{array}$ & $\begin{array}{l}10.7 \\
81.3 \\
95.1 \\
97.6\end{array}$ & $\begin{array}{r}12.6 \\
0.8 \\
1.6 \\
11.9\end{array}$ \\
\hline$P A$ & $\begin{array}{l}10^{-5} \\
10^{-4} \\
10^{-3} \\
10^{-2}\end{array}$ & $\begin{array}{l}1.009 \\
0.870 \\
0.115 \\
1.071\end{array}$ & $\begin{array}{l}5.605 \\
5.515 \\
1.339 \\
5.246\end{array}$ & $\begin{array}{l}21.5 \\
32.3 \\
91.1 \\
16.7\end{array}$ & $\begin{array}{l}20.4 \\
21.7 \\
80.9 \\
25.5\end{array}$ & $\begin{array}{l}20.6 \\
23.3 \\
82.5 \\
24.2\end{array}$ & $\begin{array}{l}13.4 \\
15.2 \\
27.9 \\
11.8\end{array}$ \\
\hline $\mathrm{T} G \mathrm{~A}$ & $\begin{array}{l}10^{-5} \\
10^{-4} \\
10^{-3} \\
10^{-2}\end{array}$ & $\begin{array}{l}1.184 \\
1.025 \\
0.852 \\
1.131\end{array}$ & $\begin{array}{l}5.435 \\
1.042 \\
0.387 \\
1.278\end{array}$ & $\begin{array}{r}7.9 \\
20.2 \\
33.7 \\
12.0\end{array}$ & $\begin{array}{l}22.9 \\
85.2 \\
94.5 \\
81.9\end{array}$ & $\begin{array}{l}20.5 \\
75.2 \\
85.1 \\
71.1\end{array}$ & $\begin{array}{r}11.0 \\
2.4 \\
1.1 \\
2.7\end{array}$ \\
\hline DMDTC & $\begin{array}{l}10^{-5} \\
10^{-4} \\
10^{-3} \\
10^{-2}\end{array}$ & $\begin{array}{l}1.517 \\
1.262 \\
0.735 \\
0.106\end{array}$ & $\begin{array}{l}1.445 \\
0.639 \\
0.466 \\
0.306\end{array}$ & $\begin{array}{r}-18.1 \\
1.8 \\
42.8 \\
91.8\end{array}$ & $\begin{array}{l}79.5 \\
90.9 \\
93.4 \\
95.7\end{array}$ & $\begin{array}{l}64.4 \\
61.8 \\
82.9 \\
95.1\end{array}$ & $\begin{array}{l}2.3 \\
1.2 \\
1.5 \\
1.2\end{array}$ \\
\hline $\mathrm{OHO}$ & $\begin{array}{l}10^{-5} \\
10^{-4} \\
10^{-3} \\
10^{-2}\end{array}$ & $\begin{array}{l}1.563 \\
1.332 \\
0.497 \\
0.052\end{array}$ & $\begin{array}{l}6.417 \\
6.030 \\
6.217 \\
3.222\end{array}$ & $\begin{array}{r}-21.6 \\
-\quad 3.7 \\
61.3 \\
95.9\end{array}$ & $\begin{array}{r}8.9 \\
14.4 \\
11.8 \\
54.3\end{array}$ & $\begin{array}{r}4.2 \\
11.6 \\
19.4 \\
60.7\end{array}$ & $\begin{array}{r}9.9 \\
10.9 \\
30.1 \\
148.9\end{array}$ \\
\hline
\end{tabular}


together with dezincification factor. The reported values are an average from two experiments. The inhibition efficiency $E$ is defined as follows; $E=\left\{\left(a_{\mathrm{o}}-a_{i}\right) / a_{\mathrm{o}}\right\} \times 100$ where $a_{\mathrm{o}}$ and $a_{i}$ are the amount of metal ions in the solution without and with inhibitor, respectively. The dezincification factor, which was introduced by Marshakov and coworkers ${ }^{11}$, is defined by the equation $z=$ $R_{S} / R_{A}$, where $R_{S}=\mathrm{Zn} / \mathrm{Cu}$ ratio in solution and $R_{A}=\mathrm{Cu} / \mathrm{Zn}$ ratio in the alloy. $R_{S}$ can be determined by chemical analysis of the solution. $R_{A}$ ( 2.4045 for the $70 / 30$ brass) is the ratio of weight $\%$ of zinc to copper in the alloy. In the absence of inhibitor $z$ was 13.2 , indicating preferential dissolution of zinc component. In the presence of inhibitor there is a tendency of decreasing $z$ value with the concentration of inhibitor.

The inhibition efficiency of BTA for the brass increased with increasing BTA concentration, particularly significant increase was observed in the concentration from $10^{-4}$ to $10^{-3} \mathrm{M}$. The same inhibition action was observed for copper dissolution with PA, DMDTC and OHO. The BTA, DMDTC and OHO gave the maximum inhibition efficiency at $10^{-2} \mathrm{M}$, while inhibition efficiency for PA and TGA increased with increasing its concentration in the range of $10^{-5}$ to $10^{-3} \mathrm{M}$ for dissolution of both copper and zinc. At $10^{-2} \mathrm{M}$ of PA and TGA, however, dissolution of both metals were accelerated by the inhibitors. The solubility of PA-metal chelating compound seemingly depends on the number of metal atoms in the compound. At lower concentration of PA the $\mathrm{PA}-(\mathrm{Cu}, \mathrm{Zn}) \mathrm{n}(\mathrm{n} \leqq 6)$ compounds may precipitate on the brass surface while at higher concentrations they may dissolve into the solution and this resulted in acceleration of anodic dissolution. Further study is necessary to verify this speculation.

These inhibitors tested apparently inhibited stronger zinc dissolution than copper dissolution under the experimental conditions except PA. This does not necessarily indicate that Zn-inhibitor complex is more protective than $\mathrm{Cu}-$ inhibitor complex, because zinc dissolution from the brass can be prevented not only by $\mathrm{Zn}$-inhibitor complex layer but by $\mathrm{Cu}$-inhibitor complex layer formed on the brass surface. A preliminary experimental result shows that BTA is not nearly as effective in complexing zinc into a stable, insoluble, film-forming products as it does in copper.
(1)

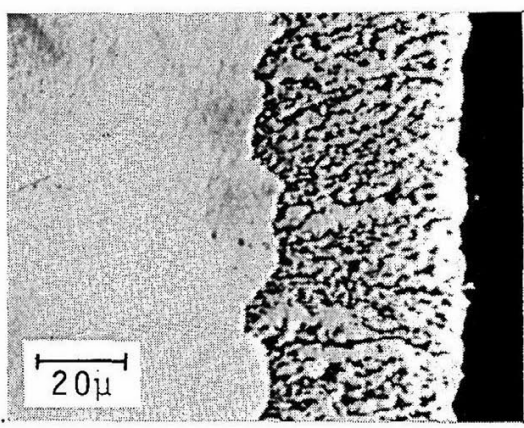

(2)

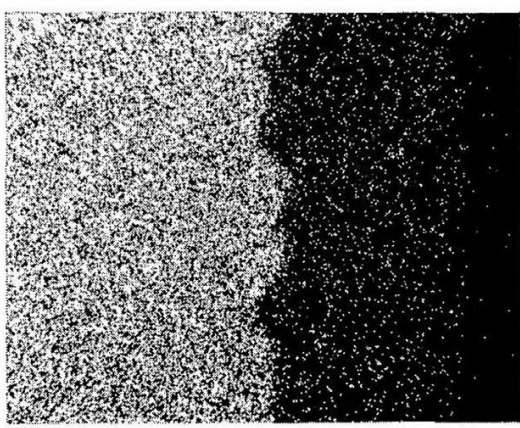

(3)

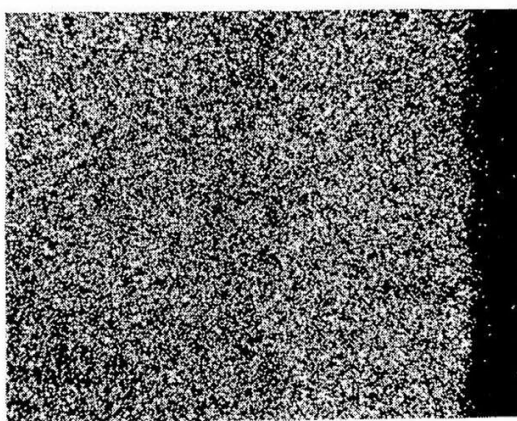

Fig. 7 Microphotographs of dezincified layer in $70 / 30$ brass. (1) SEM image (2) $\mathrm{Zn}$ distribution map (3) Cu distribution map.

On the basis of the results obtained from solution analysis, it may be assumed that the films formed on the brass surface are a mixture of cuprous-inhibitor and zinc-inhibitor complex. The inhibitive action of these inhibitors would be attributed to the formation of multilayers, i.e., brass/mainly $\mathrm{Cu}_{2} \mathrm{O} /$ inhibitor complex films, and to block active paths for dezincification ${ }^{12)}$. Chadwick and Hashemi ${ }^{13)}$ have confirmed that the surface film formed by BTA on $70 / 30$ brasses contains both copper and zinc.

Each sample used in the dezincification tests was sectioned and metallographically examined. The area of corrosion was an even layer over the entire surface area. Electron probe microanalysis of the cross section of dezincified specimen shows that a layer-type dezincified zone is composed of porous copper, as shown in Fig. 7. The X-ray 
spectra of copper and zinc distribution confirmed that the maximum concentration of zinc in the porous copper layer was $2 \mathrm{wt} \%$ of the alloy. The dezincification layer thickness increased linearly with amount of charge passed during the anodic polarization. Amount of charge of 1 coulomb $/ \mathrm{cm}^{2}$ corresponds to the formation of $1.6 \mu \mathrm{m}$ dezincification layer in $70 / 30$ brass.

\section{Conclusions}

(1) Effectiveness of the inhibitors for preventing anodic dissolution of copper and zinc from $70 / 30$ brass was in the following order; $\mathrm{PA}<$ OHO $<$ TGA $<$ DMDTC $<$ BTA.

(2) Inhibitive efficiency increased with increasing concentration and the maximum inhibition efficiency was obtained at $10^{-2} \mathrm{M}$ for BTA, DMDTC and OHO, whereas it was attained at $10^{-3} \mathrm{M}$ for PA and TGA.

(3) The dezincification attack in $70 / 30$ brass can be prevented by an addition of the most promising inhibitor such as BTA to corrosive environments. By combining BTA with tolyltriazole protection of brasses expected to be much improved $^{14)}$.

(Received April 18, 1986)

\section{References}

1) T. Notoya and T. Ishikawa: Proc. 9th Int.
Congr. Metal. Corr., 1, 333 (1984).

2) T. Notoya and T. Ishikawa: Bull. Fac. Eng. Hokkaido Univ. [117] 11 (1984).

3) T. Notoya and T. Ishikawa: Proc. 4th AsianPacific Corr. Contl. Conf., 2, 982 (1985).

4) T. Notoya: Boshoku Gijutsu (Corrosion Engineering) 27 [12] 661 (1978).

5) H. Baba, T. Kodama and T. Fujii: ibid, 34, 10 (1985).

6) O. L. Riggs, Jr.: Corrosion, 31, 127 (1979).

7) G. W. Poling and T. Notoya: ibid., 35 [1], 33 (1979).

8) H. D. Peterson, M. C. Duerstenau, R. S. Richard and J.D. Miller: Trans. Soc. Mining Engineers Dec. 388 (1965).

9) K. Nielsen and E. Rislund: Br. Corros., J., 8, May 106 (1973).

10) I. K. Marshakov and V. P. Bogdanov: Zavodskaya Laboratoria, 31, 584 (1965).

11) I. K. Marshakov, V. P. Bogdanov and S. M. Aleikina: Russian J. Phy. Chem., 38, 104 (1964).

12) T. Notoya and G. W. Poling: Corrosion, 32 [6] 216 (1976),

13) D. Chadwick and T. Hashemi: Corr. Sci., 18 [1] 39 (1978).

14) T. Notoya and G. W. Poling: Boshoku Gijutsu (Corrosion Engineering) 30, 38 (1981). 